\title{
Second thoughts on the Jarman index
}

\section{Claims being made for the underprivileged area score are unproved}

The Jarman index was introduced in $1983^{1}$ as the latest of a series of attempts ${ }^{2}$ to identify underprivileged areas for the purposes of health care planning. The index, now generally known as the underprivileged area score, was constructed from the responses of general practitioners to a question asking how much they thought each of 13 given factors increased their workload. Eight factors, which are available from census data, are now generally included in the index. These are: the percentages in the population who are elderly people living alone, children under 5 years old, in one parent families, in social class $\mathrm{V}$, unemployed, living in overcrowded conditions, changed house in the previous year, and in households headed by someone born in the new Commonwealth or Pakistan. The contribution of each factor to the final score is weighted according to the degree of importance attached to it in the original survey.

As a measure of a general practitioner's potential workload, underprivileged area scores have been validated against the opinions of local medical committees, ${ }^{3}$ against mortality from causes of death deemed amenable to treatment by general practitioners and incidence of diseases for which general practitioner intervention could be important, ${ }^{4}$ against low birth weight and prevalence of disability, ${ }^{5}$ and against survey morbidity and consultation data. ${ }^{6}$ Relating underprivileged area scores to the actual amount of work performed by general practitioners has been more difficult. In Manchester it was found that general practitioners with surgeries in the worst wards according to underprivileged area scores spent less total time with their patients. ${ }^{5}$ Work done out of hours by general practitioners does not seem to be well characterised by underprivileged area scores, ${ }^{7-9}$ nor are there straightforward associations between single items of the underprivileged area index and workload. For example, one study found south Asian men to have high consultation rates while those for Afro-Caribbeans were low. ${ }^{10}$

In addition to the lack of evidence to show that actual general practitioner workload is related to underprivileged area scores, several other criticisms of the index have been made, ${ }^{11} 12$ and these are amplified in two articles in this issue (383-6, 393-6). ${ }^{1314}$ By necessity the underprivileged area scores rely on out of date census data; the validity of the statistical manipulations and weightings used in their computation is in doubt; they are biased towards London and away from the north of England; and there can be considerable heterogeneity of socioeconomic circumstances within the areas for which the scores are computed.
In the light of these wide ranging criticisms of the index we should, perhaps, reconsider what underprivileged area scores are meant for. The original article describing the index ${ }^{1}$ was ambiguous about its purpose. ${ }^{5}$ The concept of an "underprivileged area" might embrace those in which the difficulties of primary care were high, where the need for health care was greatest, where general practitioner workload was the most demanding, where there was most pressure on services, or where general practitioners subjectively felt work was most arduous. Professor Jarman was careful to avoid advocating any particular use of the index ${ }^{1315}$ - but the decision not to include one of the original 13 items (the percentage of the population over 65 ) in the final index because "there [is] already weighting for the elderly in general practitioners' remuneration" makes little sense unless use for payment purposes was being considered. ${ }^{1}$

How, then, has the underprivileged area index been used in practice? It has been included in the new general practitioner contract to establish deprived area payments to practices with patients living in wards with underprivileged area scores over a certain value, ${ }^{16}$ it was considered in the Resource Allocation Working Party (RAWP) review for use in resource allocation, ${ }^{17}$ and it has been treated as a marker of deprivation in the consideration of social inequalities in health. ${ }^{18}$ Yet the attributes of the measures required for these different purposes vary. Let us look at the appropriateness of the underprivileged area index in each of these settings.

Regarding deprived area payments for general practitioners, the main source of contention has been the threshold set for receiving additional payments. Currently $9 \%$ of the population of England and Wales is covered by payments, but the BMA's General Medical Services Committee is arguing for a reduction in the threshold to include $20 \%$ of the population. ${ }^{19}$ A more fundamental problem concerns the exact function of the payments. Are they intended to compensate general practitioners for the additional workload in deprived areas, or are they to serve as incentives to encourage general practitioners to work in areas in which recruitment of practitioners has traditionally been difficult? If the former is the case then underprivileged area scores seem not to fulfil the desired function, and further empirical research is needed regarding influences on workload. If, on the other hand, the payments are to serve purely as incentives, then an index based on the subjective opinions of general practitioners could be appropriate. The degree of desirability, or lack of desirability, of a particular work location to general practitioners 
will not be influenced purely by the expected workload. A survey explicitly focused on which factors necessitate compensation seems to be needed.

Similar considerations apply to the other uses to which underprivileged area scores have been put. In the (now superseded) RAWP review the index was included in the resource allocation formula after criticism that the original formula did not take account of social deprivation. ${ }^{20}$ The research commissioned for the RAWP review did not, however, show that the use of this index would improve the fit between resource allocation and either need or demand for health services. ${ }^{21}$ There is no reason to believe that the use of other deprivation indices would do any better. ${ }^{22}$ The use of indices requires that a relation has been shown between measurements and the underlying factors which they are supposedly indexing. Stating that the underprivileged area score "is a measure of workload or pressure on the services of general practitioners" 23 is premature, and the index cannot adequately substitute for empirically validated measures in the fields in which it is being used.

GEORGE DAVEY SMITH

Lecturer in Epidemiology,

Department of Epidemiology and Population Sciences,

London School of Hygiene and Tropical Medicine,

London WCIE 7HT
1 Jarman B. Identification of underprivileged areas. BMF 1983;286:1705-8.

2 Carstairs V. Small area analysis and health service research. Community Med 1981;3:131-9. Jarman B. Underprivileged areas: validation and distribution of scores. BMF 1984;289:1587-92. . Leavey R, Wood J. Does the underprivileged area index work? BMF 1985;291:709-11.

6 Curtis SE Use of survey data and small area statistics to assess the link between individual morbidity and neighbourhood deprivation. $\mathcal{F}$ Epidemiol Community Health 1990;44:62-8.

Livingstone AE, Jewell JA, Robson J. Twenty four hour care in inner cities: two years' out of hours workload in east London obson J. Twenty four hour care in inner

8 Pitts J, Whitby M. Out of hours workload of a suburban general practice: deprivation or expectation. BMF 1990;300:1113-s.

Main JA, Main PGN. Twenty four hour care in inner cities. BMf 1989;299:627.

10 Gillam SJ, Jarman B, White P, Law R. Ethnic differences in consultation rates in urban general practice. BMF 1989;299:953-7.

1 Scott-Samuel A. Identification of underprivileged areas. BMf 1983;287:130.

12 Thunhurst C. The analysis of small area statistics and planning for health. Statistician 1985;34: 93-106

13 Talbot R. Underprivileged areas and health care planning: implications of use of Jarman indicators of health care deprivation. BMF 1991;302:383-6.

14 Carr-Hill RA, Sheldon T. Designing a deprivation payment for general practitioners: the UPA wonderland. $B M \mathcal{F}$ 1991;302:393-6.

15 Jarman B. Identification of underprivileged areas. BMf 1983;287:130-1.

16 Health Departments of Great Britain. General practice in the National Health Service. The 1990 Contrace London: HMSO, 1989.

7 Department of Health and Social Security. Review of the Resource Allocation Working Party formula: final report by the NHS Management Board. London: HMSO, 1988.

18 Whitehead $M$. The health divide. In: Townsend P, Davidson N, Whitehead M, eds. Inequalities in health: the Black report and the health divide. Harmondsworth: Penguin, 1988:215-356.

19 Delamothe T. Deprived area payments. BMF 1990;300:1609-10.

20 Smith J. RAWP revisited. $B M \mathcal{J}$ 1987;295:1015.

21 Mays N. NHS Resource allocation after the 1989 white paper: a critique of the research for the RAWP review. Community Med 1989;11:173-86.

22 Carstairs V, Morris R. Deprivation, mortality and resource allocation. Community Med 1989;11 $364-72$

23 Jarman B, Bosanquet N, Rice P, Dollimore N, Leese B. Uptake of immunisation in district health authorities in England. BMF 1988;296:1775-8.

\section{Axillary dissection in primary breast cancer}

\section{The benefits of node clearance warrant reappraisal}

Metastases in axillary lymph nodes are the most important determinant of prognosis in patients with primary breast cancer. The management of these nodes is, however, controversial. Instead of axillary node clearance many surgeons now opt for axillary node sampling with radiotherapy to the axilla for node positive patients in an effort to reduce the morbidity associated with surgery for breast cancer. The advantages of sampling may, however, have been overestimated and those of clearance underestimated.

Morbidity in patients undergoing axillary node clearance is considerable: seromas occur in up to three fifths, all have patches of numbness or paraesthesia, shoulder mobility will be reduced, and some will develop chronic lymphoedema. Nevertheless, recent evidence suggests that surgeons can reduce the incidence of seroma considerably by paying careful attention to closing dead space. ${ }^{1}$ They can also prevent sensory loss by preserving the intercostobrachial nerve without compromising the extent of axillary dissection. Although the incidence of both seromas and sensory loss is negligible in patients who undergo axillary node sampling with radiotherapy, Aitken et al showed greater reduction in the mobility of the shoulder joint in these patients than in those undergoing node clearance. ${ }^{2}$ This influenced daily activity to a severe degree in $14 \%$ of the sampling group. Arm swelling was similar in both groups and only minor.

Although axillary lymph node sampling may allow accurate determination of metastasis in lymph nodes when expertly performed, ${ }^{3}$ in one multicentre study no lymph nodes were obtained in up to a quarter of patients in whom sampling was performed. ${ }^{+}$The opportunity to improve survival in node positive premenopausal women by using adjuvant chemotherapy will be lost if their nodal status is not determined accurately at presentation. Similarly, proper determination of nodal status is important when evaluating the benefits of adjuvant chemotherapy in node negative patients. ${ }^{5}$ In addition, serial sectioning of lymph nodes and immunohisto- chemical staining have shown that almost a third of node negative patients have micrometastases, ${ }^{67}$ the presence of which correlates positively with recurrence. ${ }^{7}$ Should further studies confirm these findings this group of patients will also require evaluation in trials of adjuvant chemotherapy for patients with node negative breast cancer.

Clinically evident recurrence in axillary nodes, preventable by axillary node clearance, ${ }^{8}$ was present in just over one fifth of patients who underwent node sampling in a study by Locker et al after a short follow up period. ${ }^{9}$ Untreated, such recurrence invades the brachial plexus and subclavian vessels, resulting in severe pain and lymphoedema, both of which are difficult to control. Nevertheless, Fisher et al showed that delay in treating the axilla in clinically node negative patients who subsequently became node positive did not adversely affect their survival. ${ }^{11}$ Moreover, the survival rates for node positive patients randomised to receive either radical mastectomy alone or mastectomy without axillary dissection but with regional irradiation were equivalent at 10 years. These studies, performed before the role of adjuvant chemotherapy for breast cancer had become established, suggest that delaying axillary clearance in otherwise adequately treated patients until they develop an axillary recurrence is unlikely to influence survival. ${ }^{10}$ This assumption has not, however, been tested in a properly controlled clinical trial.

Axillary node clearance performed through a separate axillary incision in conservative surgery for breast cancer is technically more difficult than clearance performed during mastectomy, and extra care is needed to ensure adequate clearance of all axillary lymph nodes. Removal of level II and III lymph nodes, made easier by dividing the pectoralis minor, is important for local disease control in node positive patients. A properly performed level I axillary node dissection, however, is adequate for staging. ${ }^{.1}$ Specimens taken at node clearance should yield an average of 20 or more lymph nodes for each specimen. Specimens taken at sampling should 